\title{
Constructional Hierarchy and Features of the There Construction
}

\author{
Bo Li \\ School of Foreign Languages \\ China West Normal University, CWNU \\ Nanchong, China
}

\begin{abstract}
The There Construction, as a very important and widely used construction in English has aroused extensive concern of the scholars in the research field. Previous studies predominantly concentrate on such issues as its subject, nonconcord in the construction, the definiteness effect of NP after VP, its classification and its formation. Little attention has been paid to the syntactic and semantic features of the construction. Thus, we elaborate the constructional features and the constructional hierarchical relationship of the There Construction in present English on the basis of data collection of COCA (Corpus of Contemporary American English). It might also benefit the further academic study, teaching and acquisition of the There Construction.
\end{abstract}

Keywords-There Construction; construction grammar; constructional features; constructional hierarchy

\section{INTRODUCTION}

The There Construction is an old but complex language structure which has appeared in 1500s. When it comes to the constructional features of the There Construction, we have to know its classification in the first place.

Almost all previous studies on There Constructions confine its constructional meaning to the existence of an event. Thus, in the sights of many scholars, they insist that the There Construction can have diverse syntactic form but they hold only one meaning around existent of an event (Sawyer 1973; Milsark 1979; Quirk, et al 1985; Hu 1988; Lumsden 1988; Huddleston \& Pullum 2002; Mcnally 1998; Biber, et al 1999; Zhang 1997, Zhang 2001 etc.)

However, Lakoff (1987: 468) claims that the There Construction is provided with another meaning, the deictic meaning, which is relative to the context in which the sentence is uttered. So he classifies the There Construction into two categories: the existential There Construction and the deictic There Construction. In fact, many scholars (Hannay 1985; Lumsden 1988; Zhang 2008) also point out that some There Constructions hold some presentational functions which can be interpreted as the deictic function, that is to say, Lakoff's classification in some way reflects a real situation of the use of the There Construction. Lakoff (1987) lists some major syntactic differences between the constructions but those

Supported by the Fundamental Research Funds of China West Normal University (Grant No. 17D045) differences are on the basis of some transformation rules which are based on their own meaning, that is to say, there are no clear and distinct syntactic features between these two subconstructions and he just takes them as two kinds of meanings of the There Construction.

According to construction grammar, construction is a formmeaning pair correspondence, or rather, different meanings relates to different forms. Since Lakoff emphasizes that there are different meanings of the There Construction, so their form may be different. So in order to find out the answer we turn to corpus for help. COCA (Corpus of Contemporary American English) is used as the data source for statistical analysis. This thesis brings to bear empirical evidence concerning the constructional hierarchy and the constructional features including syntactic and semantic features of the There Construction of the There Construction.

\section{CONSTRUCTIONAL HIERARCHY OF THE THERE CONSTRUCTION}

According to COCA, present synchronic English corpus ranging from 1990 to 2015 which can largely reflect real language use in recent years among native speakers. Two different There Constructions are sorted out and their forms are as the following:
a. There + VP+ Ind. NP + (ADV)
b. There $+\mathrm{VP}+\mathrm{De} . \mathrm{NP}+(\mathrm{ADV})$

The only difference between the two sub-There Constructions lies in the definiteness of NP. After elaborate analysis of context, it shows that not only the syntactic features are different but also its related semantic features. In fact, a is used to denote "existence /occurrence of something", whereas $\mathrm{b}$ is used to denote "picking out location of the entity in motion or not in motion". Some examples are:

- 1. The smiling young woman wears a white headscarf and hides her face with a scarf when photographed. She says she'll be done training within two months and isn't afraid to return. There's a clinic where she can leave her son, Salim, who is nearly 3. (COCA)

- 2. For me, my husband comes in and he says, "Honey, who am I voting for?" And I say "if you vote 
Republican, there is the couch. If you vote Democrat, come into bed, darling - ". (COCA)

In sentence 1, the indefinite determiner "the" is used to modify the word "clinic", which appears as new information, denoting the meaning of "existence". Thus, this sentence can be paraphrased in the following "there exists a clinic where she can leave her children." This coincides the fact revealed by also many linguists that NP should be indefinite (Bull 1943; Lyons 1977; Close 1977; Leech 1971/1982). Sentence 2 is talking about a couple's for voting. When the dominant wife warned his husband that if he voted republican then he would have to sleep on the couch for the whole night, using the definite article the before couch, it can be inferred that the couch is an old information, which means that the couch is existed. When it is used with "there", it fails to denote the existentials but the deictics picking out where the couch is.

Our classification happens to coincide with Lakoff's study. Lakoff points out the deictic meaning of the There Construction, things are getting different and interesting but unfortunately he forgot to make forms of both types clearly. In present study, we believe that the There Construction with definite NP straightly refers to the deictic There Construction. As is known to all, definiteness in grammar refers to the syntactic reference form before NP such as demonstrative determiner, possessive determiner, genitive noun, and definite article. In pragmatics, definiteness refers to the old information in context or co-text. On the whole, they correspond with each other, that is to say, the use of definitive means that NP has already appeared before and can be treated as the anaphoric reference. Bolinger (1977: 92) also claims that the existential there just brings something into awareness and leads us to the set stage. Thus, in the There Construction, when something is mentioned for the first time, it should be indefinite and if it has already been mentioned, it has to be definite. Thus, a definite NP is a must in the deictic There Construction.

In summary, the There Construction family can be represented as the following Figure ( $\mathrm{Cxn}$ is short for construction; Ex. is short for existential; Dei. is short for deictic):

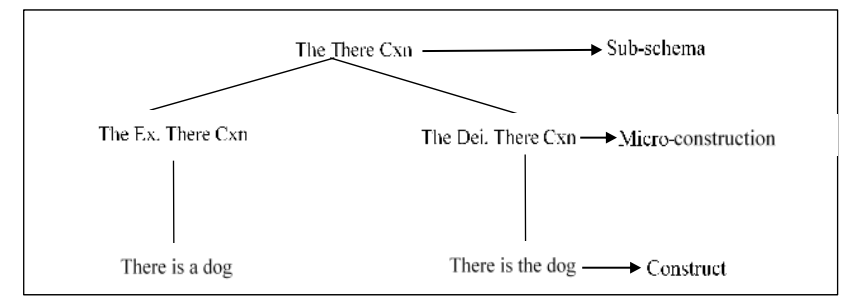

Fig. 1. Constructional Hierarchy for the There Cxn.

Thus, this above figure presents a constructional network of the There Construction. The top layer is the There Construction as the subschema of upper macro-construction about existentials and deictics. The middle layer is sub-constructions of the upper schema including the existential There Construction and the deictic There Construction, and the bottom layer is constructs. However, since we have outlined the classification of the There Construction, but we still need to figure out its constructional features concerning the token distribution of the There Cxn, syntactic features (tense, VPs, NPs, final parts).

\section{CONSTRUCTIONAL FEATURES OF THE THERE CONSTRUCTION}

According to the classification, in the next two sections, we would have an elaborate description on syntactic and semantic features of the There construction.

\section{A. Syntactic and Semantic Features of the Existential There Construction}

Further descriptions over this construction would be made on the basis of COCA. In the corpus, 753746 tokens of the There construction have been searched out including 717747 tokens of the existential There construction and 35999 tokens of the deictic There construction. Since VP consists of BE and $\mathrm{Vv}$, so we would elaborate the syntactic characteristics from these two perspectives respectively. According to COCA, it demonstrates that There are five presentations of the existential There construction distinguished by five forms of $\mathrm{BE}$ as the predicate:

i. The present tense of BE: am, is, are;

e.g.:

1) There is a house to the north.

2) There are some reports of congestion in the core.

ii. The past tense of BE: was, were;

e.g.:

3) There was preparation that we know started months ago.

4) There were 700 priests for a population of 6 million.

iii. Abbreviation form of Is and Are: 's; 're;

e.g.:

5) There's a saying common in education.

6) There're a lot of them out there that don't help much.

In those examples from 1 to 6 , no matter what forms of $\mathrm{BE}$, it always denotes a static existence. Since BE is static, so the existential There Construction with BE is static as well. However, there are always some tiny differences. In fact, i is used to denote events existing now, whereas ii is used to denote events existing in the past. iii can be taken as variants of $i$.

As regards VP, according to COCA, those 213 verbs below are used in the existential There Construction (Sort Alphabetically):

A: abide, affect, analyze, appear, arise, ariseth, arrive, ascend, attach;

B: beat, become, begin, blow, break, burn, burst;

C: carouse, can, can't, catch, cease, chance, close, coach, coil, come, cometh, commence, concern, continue, could, correspond, crawl, creep, cross, crop, crouch, crown, curl;

D: develop, descend, do, don't, drift; 
E: earn, eat, echo, emerge, ensue, enter, end, erupt, escape, exist, exude;

F: face, favor, feed, fell, fester, figure, fine, fall, fire, flash, fly, flow, flourish, float, followeth, follow, form;

G: gather, gain, glisten, go, get, graduate, grow, gush;

$\mathrm{H}$ : have, hope, hover, howl, highlight, hang;

I: include, intrude, issue;

$\mathrm{K}$ : keep

L: lack, lay, leave, legislate, let, lay, linger, leap, lie, live, loll, look, lurk, loom; must;

M: may, make, march, marinate, merge, move, mourn,

$\mathrm{N}$ : need, nestle;

O: occur, open, operate, oppose, ought;

P: park, pass, persist, perch, perform, play, place, pledge, pluck, present, pour, put, promise, prove;

Q: quick;

$\mathrm{R}$ : race, rage, run, rest, require, re-appear, reign, rejoin, remain, reside, reside, result, return, reverberate, ride, rise, roam, roll, rust;

S: sail, say, scar, scuppernong, see, seem, seep, shall, shatter, should, sit, sleep, slip, slumber, soar, sound, speak, spring, spread, spurt, squat, start, state, stay, steal, step, stand, stop, stretch, stuff, survive, suck, surface, swell, swim;

T: take, talk, tell, tare, tend, travel, transpire, trickle, trouble, try, turn;

$\mathrm{U}$ : use, unite, unroll;

V: value;

W: wait, want, wave, wee, will, wilt, witness, work, wus, wuz, wove;

\section{Y: yawn;}

According to Dixon (2005), words can be grouped together in a natural way into a large class that has a component with common meaning. He refers to these as semantic types. Thus, at the level of semantic words can be arranged in semantic type with a common meaning element, for example, verbs begin, start, commence, finish, cease, stop, continue and a few others all make up one type the BEGINNING type .

Thus, by analyzing each word's meaning, they can be grouped into those semantic types below:

- the MOTION type: arrive, ascend ,awake, blow, break, burst, go, catch, come, cometh, crawl, creep, cross, crop, descend, echo, enter, escape, exude, feed, fall, fester, fire, flash, fly, flash, flow, followeth, follow, form, gain, gather, glisten, go, graduate, gush, leap, leave, loom, marinate, march, move, operate, pass, play, pluck, pour, run, return, rise, roam, ride, sail, seep, slip, steal, step, stuff, surface, swim, take, travel, trickle, trouble, turn, value, wave, wee, work, weave;
- the AFFECT type: affect, attach, burn, coil, curl, erupt, lack, rage, reverberate, roll, rust, scar, shatter, spring, spread, spurt, stretch, swell, transpire, unite, unroll, wilt, flourish, grow, quicken;

- the REST type: abide, cease, crouch, drift, exist, float, hover, hang, include, lay, leave, lie, linger, live, loll, lurk, merge, nestle, park, perch, place, put, rest, reign, remain, reside, rest, sit, squat, stay, stand, stop, tare, wait;

- the CORPOREAL type: eat, carouse, crown, face, howl, mourn, slumber, sleep, soar, sound, suck, yawn;

- the BEGINNING type: arise, ariseth, commence, continue, emerge, ensue, end, persist, start, survive;

- the MAKING type: coach, develop, earn, get, issue, keep, legislate, let, make, reign;

- the SEEM type: appear, chance, figure, occur, re-appear, result, seem;

- the WANTING type: hope, need, require, tend, try, want, pledge, promise;

- the COMPETITION type: beat, become, oppose, race;

- the ATTENTION type: concern, look, see, witnesses;

- the SPEAKING type: say, speak, state, talk, tell;

- the INTERVENE type: intercede, intrude;

- the PUBLISHMENT type: fine;

- the EMPHASIZE type: highlight;

- the GIVING type: present, prove;

- the OPENING type: open, close;

- the USING type: use;

- the LINKING type: correspond, favor;

- the ANALYZE type: analyze;

- the MODALS type: can, can't, will, do, ought;

- the SEMI-MODALS type: have (have done);

According to present corpus, above 21 concluded semantic types have demonstrated what kind of verbs under those semantic types can be used in the There Construction. Some conclusions can be made as the followings:

First, all of verbs in those types can be used in the present tense and past tense as BE. Not only $\mathrm{BE}$ can be used in different tense but also $\mathrm{V}$ can be either, e.g.:

7) There go the Bulgars, the Bosnians;

8) There ate no alternatives, just as there are no alternatives to the game I played.

Second, verbs in the MODALS and the SEMI-MODALS types cannot be existed independently but appear with only participle form and perfect tense of BE, e.g.: 
9) There can also be incidental expenses involved in helping participants get the most out of the event (participle form), and

10) Since I have been a person known in the public, there have been few times that I've been anywhere and not been sold out, (perfect tense)

All semantic types describe a dynamic process of existence. In other words, the existential There Construction in the 21 semantic types tends to focus on the occurrence of an event. Similar to the there BE, "there" in the there V is also a grammatical subject, which arouse hearers or readers' attention.

Third, according to those semantic types, we may find that due to verbs' dynamic feature, this construction becomes dynamic as well so as to describe the dynamic existence, or more accurately, occurrence. In other words, the use of $\mathrm{V}$ has been extended from only BE to different $\mathrm{V}$ within words of 21 semantic types above and its semantic meaning also has been extend from the static existence of event to the dynamic meaning.

$\mathrm{NP}$ after $\mathrm{VP}$ in the there $\mathrm{Vv}$ are as similar as those in the there BE. e.g.:

11) There arose problems if a man owned his own piece of land in the countryside.

12) There follows a sequence of short moments from this nightmare flight.

Since NPs in the existential There Construction are indefinite, so according to the corpus data, two forms of NPs can denote the indefiniteness: the one is a noun without change in number or mass noun (not including proper name), e.g.:

13) There is also concern that powerful actors will use climate change as an excuse to conduct.

The other one is those indefinite modifiers that can be added before NP:

i. INDEFINITE DETERMINER (such as no, some, any, a, each, every, enough, either, neither, all, both, half, several, many, much, (a) few, (a) little, other, another)

e.g.:

14) There are some very angry people waiting there for me, and they might even put me in.

15) There were several impassioned, impassioned speeches made about this loss.

ii. CARDINAL NUMERAL (such as one, two, three, four, five......)

e.g.:

16) There is one item of the late professor's loot that I am somewhat interested in.

17) There were two pairs that they gave to us and they did not work.

iii. ORDINAL NUMERAL (such as first, second, third, fourth......) e.g.:

18) There was first silence followed by a clearing of the throat.

19) Sometimes, in life, there are second chances.

iv. FRACTIONAL NUMERAL (such as twice, three times......)e.g.:

20) There are twice as many people with mental illness in jails than there are in public psychiatric hospitals.

21) There were three times we had to start all over again.

v. QUANTIFIER (such as a lot of, lots of, plenty of, a great of, a good deal of, a large of, a small amount of, a quantity of, a great of, a good number of......)

e.g.:

22) There's a lot of worse things that have been said.

23) There was a good deal of information in the old records and newspapers, as well as in Hinton.

Besides, the final part of the existential There Construction still needs to be paid attention. According to our statistics, it contains considerable kinds, focusing on temporal adverbs, locational adverbs, complements etc.:

e.g.:

24) There was one moment when I shifted into the big ring. (temporal adverb)

25) There's a bus upside down in the ditch. (locational adverb)

26) There appear to be small blemishes on her face, and bruises or "love-bites". (locational adverb)

27) There are some things conceived which can't be born. (complement)

28) There are several possible explanations for this observation, including relatively recent emergence of Hantaviruses in the region. (complement)There arose the present belief that the universe is expanding. (complement)

Sometimes, on the other hand, the final parts may be omitted, especially when it refers to some location, e.g.:

29) There are several possible outcomes. (omitted)

30) There arose such a clatter. (omitted)

It can be predicted that final parts in sentence 24 to 30 are the extension of NP (such as one moment in 24, a bus in 25, some things in 27 , explanations in 28), or we can say, the final part is semantically a predicate and it is predicated of NP (Lakoff 1987: 503). As to the phenomenon of omission, if the location has been known and shared mutually, there is no need to mention twice. But if the location is new for the hearers or readers, it would be better to put it forward.

Furthermore, over $99 \%$ tokens in corpus, the number of $\mathrm{V}$ is consistent with NPs, which is in concord with most linguists' assumptions and declarations. Also the NP as the notional subject has been demonstrated. The number of NP is in 
concord with the notional subject. Thus, since NP as the real subject is regarded as the focus, whereas there is just a grammatical subject, referring to bring something new into awareness.

After discussion on syntactic characters of this construction, we shift to its semantic meaning. As we have analyzed above, from all those examples we pick out of COCA, we may find that the existential construction with $\mathrm{V}$ tends to denote kind of static existence. Except for there $\mathrm{V}$, since $\mathrm{V}$ possesses a dynamic meaning, so the existential There Construction with $\mathrm{V}$ is dynamic, referring to denoting the occurrence of some entities.

On the whole, the existential There Construction denotes existence or occurrence of something new. In other words, the information focus is on something or somebody, denoting their existence but not their location (Klaus 2002).

Thus, according to data analysis, the form-meaning pairing schema can be displayed as the following:

There VP Ind. NP [Final Phrase] $\rightarrow$ existence of something/occurrence of something

\section{B. Syntactic and Semantic Features of the Deictic There Construction}

35999 tokens of the deictic There Construction have been found, including 34877 tokens with BE and 93194 tokens with $\mathrm{V}$, and firstly the syntactic features of BE in the deictic There Construction with $\mathrm{BE}$ would be put forward as follows:

i. The present tense of BE: am, is, are

31) Where two or three are gathered together in my name, there am I in the midst of them.

32) There is the faint, inexplicable scent of vinegar in the air.

33) There are these incredibly high rates and the pattern we see is so very different from the rest.

ii. the past tense of $\mathrm{BE}$ : was, were

34) There was such an emphasis today placed on her personal narrative.

35) There were the bodies with faces in the front mirror.

iii. Abbreviation form of: 's, 're

36) There's such inequality in the developing world that it just seemed ethically wrong for me to turn.

37) There're the planets to look at too, depending on the time of year.

Obviously, as a whole, all these sentences above in the deictic There Construction are quite similar to those occurring of $\mathrm{BE}$ in the existential There Construction. But in the first item, am as a special item cannot be used in the existential one for the word I after am refers to the pronoun which is definite and can appear only in the deictic one.
Through statistical analysis on data in COCA, V which can be used in the deictic There Construction (Sort Alphabetically) are:

A: arise, appear, await

B: begin, burn

C: come, commence

D: develop, dwell

E: eat, emerge, exist

F: follow

G: go, grow

$\mathrm{H}$ : hang, have,

L: lay, lie, linger, live, loom, lurk

M: marry

O: occur

$\mathrm{R}$ : remain, rest, respond

S: sit, stand, speak

T: thunder

W: waft, wait, will

By numbers, words in each letter seem much less than those in the existential There Construction. How about their semantic type? By analyzing each word's meaning, they can be grouped into those 11 semantic types below and all of verbs can be used in the present tense and past tense as BE.

1. The REST type: await, dwell, exist, hang, lay, linger, live, lurk, remain, rest, sit, stand, wait

2. The BEGINNING type: arise, begin, commence, emerge

3. The MOTION type: come, follow, go, lie, loom, waft,

4. The SEEM type: appear, occur

5. The AFFECT type: burn, grow

6. The LINKING type: marry, respond

7. The MAKING type: develop

8. The CORPOREAL type: eat

9. The SPEAKING type: speak

10. The SEMI-MODALS type: have

11. The MODALS type: will

Types in the deictic There Construction are also much less than those in the existential one. The WANTING type, the COMPETITION type, the ATTENTION type, the INTERVENE type, the PUBLISHMENT type, the EMPHASIZE type, the GIVING type, the OPENING type, the USING type, the ANALYZE type cannot be found in the deictic There Construction. A comparison would be shown as the following: 


\begin{tabular}{|l|l|}
\hline WANTING & MOTION \\
COMPETITION & AFFECT \\
ATTENTION & REST \\
INTERVENE & CORPOREAL \\
PUBLISHMENT & BEGINNING \\
EMPHASIZE & MAKINING \\
OPENING & SEEM \\
USING & SPEAKING \\
ANALYZE & LINKING \\
& MODALS \\
The Ex. There Cxn (21) & The DeC. There Cxn (11) \\
& \\
& \\
& \\
& \\
& \\
& \\
&
\end{tabular}

Fig. 2. Semantic Types of VP in the Ex. There Cxn and the De. There Cxn.

In the above figure, the big solid line square belongs to the existential There Construction while the small dotted square is confined to the detictic There Construction. The solid one includes the dotted one. We can see that constrains on $\mathrm{V}$ in the deictic There Construction are much more than those in the existential There Construction. Thus, all constraints on $\mathrm{V}$ in the deictic There Construction are consistent with those in the existential There Construction.

Since this is a deictic construction, the types of determiners have to be mentioned. According to the analysis of data in COCA, we find that all those determiners used in the deictic There Construction with BE all appear as well in this with V.

In those examples from 33 to 39 above, words like the, these and such above are used before NPs in the deictic There Construction. They are all determiners.

However, determiners that can be used in this construction are more than that. In the nest part, we explore how many types of NPs appear in our data collection.

They are:

i. Definite Article (such as the), e.g.:

38) There is the Genetic Information Nondiscrimination $A c t$, or GINA.

39) There came the sound of magnetic boots clanking against metal.

ii. Demonstrative Determiner (such as this, that, these, those, such)

e.g.:

40) There's this really cool book that Sonia Jackson Myles came out with.

41) There came this delightful forest nymph, stitching my wounds and serving me caviar. about.

42) There go those problems everyone was complaining

iii. Possessive Determiner (such as my, your, his, her, our, your, their, its)

e.g.:

43) There is my grandfather, fourth grade education.

44) There howl your pagans.

45) There were her two cousins, Marc and Jake, but both of them had moved.
46) There are their Cub Scout and Boy Scout shirts with all of their patches.

iv. Genitive noun (such as Dawkins's etc.) e.g.:

47) Then there was Dawkins's tendency to tell elaborate stories of pre-Chaucerian England in a nostalgic, anecdotal way.

48) There was Clement's grandmother and that Anton made his way to California's sunlight without her.

v. Pronoun (such as I, me, you, he, him, she, her, they, them, it)

e.g.:

49) There's you, there's Lara.

50) There is he a state, Utah, which has succeeded in passing a bipartisan immigration.

51) In caves of ice and on the shoulders of volcanoes, there may they be found in numbers.

vii. Proper name (such as God, John, Madonna, etc.)

52) There was God looking down from the clouds as if from out of a window.

53) There's John right there in Miami.

54) There's Madonna and her multiple partners writhing back and forth.

Firstly, this above conclusion shows that people are likely to give priority to the definite article in the deictic There Construction and the use of the demonstrative determiner also occupies a high percentage. Possessive determiner and Pronoun are less frequently used. Genitive noun is the one people use the least.

Secondly, genitive noun and proper name may be only used in the deictic There Construction with BE. The other types may be employed in both.

Thirdly, some determiners can be used after some indefinite modifiers such as indefinite determiner and quantifier, e.g.:

55) But there were all those stories in the paper at the time, mothers who didn't know their husbands were molesting their daughters.

56) There are a lot of the right people in his corner.

As to final parts, just like the existential There Construction, indefinitely large number of final parts can occur, e.g.:

57) There is that moment when she's saying, and I thought, am I going. (temporal adverb)

58) There is the Rod Carter kid at Galena Park. (locational adverb)

59) There is the possibility now of screening embryos to make sure they do not have certain. (complement) 
60) There is such amount of self-observation, thinking things through and then making a new decision. (complement)

61) There is the public image and the private reality. (omitted)

From 57 to 60, final parts continue further explanations over that moment, the Rod Carter kid, the possibility now of screening embryos, and such amount of self-observation. 61 omits the final in that it must have been acknowledged or mentioned just now.

Thus, how about its semantic meaning? What is the meaning of there in this construction? Totally different from "there" in the existential There Construction as a grammatical subject, "there" here refers to the location which is the focus of this construction, pointing out where something is existed right now.

Thus, the deictic There Construction is used to pick out the entity or event that has already existed or occurred before but now has appeared again from its location. Focus is on the location but not as the existentials shows on the entity.

The deictic There Construction with BE is used to pick out something that is static due to the static nature of $\mathrm{BE}$ while $\mathrm{V}$ is used to point out something that is moving due to the dynamic nature of $\mathrm{V}$.

Thus, the form-meaning pairing schema of the deictic There Construction can be displayed as the following:

[[There VP De. NPs [Final Phrase]] $\rightarrow$ [picking out the position of sth. static or in motion]

Therefore, as two independent sub-constructions of the There Construction, their exhibit different constructional features, which can be abstracted as in "Table I":

TABLE I. Difference BetweEn The EX. THERE CXN AND THE DEI. THERE CXN

\begin{tabular}{|c|c|c|c|c|c|}
\hline & & \multicolumn{2}{|c|}{ The Ex. There Cxn } & \multicolumn{2}{|c|}{ The Dei. There Cxn } \\
\hline & & STAPIC & DYNAMIC & STATIC & DYNAMIC \\
\hline \multirow[t]{5}{*}{$\begin{array}{l}\text { Syntactic } \\
\text { features }\end{array}$} & Tense & $\begin{array}{l}\text { present } \\
\text { tense, past } \\
\text { tense }\end{array}$ & $\begin{array}{l}\text { present tense, } \\
\text { past tense, } \\
\text { perfect tense }\end{array}$ & $\begin{array}{l}\text { present tense, } \\
\text { past tense }\end{array}$ & $\begin{array}{l}\text { present tense, } \\
\text { past tense }\end{array}$ \\
\hline & VP & $\begin{array}{l}\mathrm{Be}(\mathrm{is} / \mathrm{s}, \\
\text { are/'re) }\end{array}$ & $\begin{array}{l}21 \text { semantic } \\
\text { types }\end{array}$ & $\begin{array}{l}\mathrm{BE}(\mathrm{am}, \mathrm{is} / \mathrm{s}, \\
\text { are/'re) }\end{array}$ & $\begin{array}{l}11 \text { semantic } \\
\text { types (included } \\
\text { in the } 21 \\
\text { semantic types) }\end{array}$ \\
\hline & NP & \multicolumn{2}{|c|}{$\begin{array}{l}\text { indefinite /determiner/ } \\
\text { cardinal/numeral/ ordinal } \\
\text { numeral/ fractional } \\
\text { numeral quantifier }+\mathbf{n} . \\
\end{array}$} & \multicolumn{2}{|c|}{$\begin{array}{l}\text { definite article/ demonstrative } \\
\text { determiner/ possessive } \\
\text { determiner/genitive noun/ } \\
\text { pronoun/proper name+n. }\end{array}$} \\
\hline & Final Parts & \multicolumn{2}{|c|}{$\begin{array}{l}\text { temporal adverbs; } \\
\text { locational adverbs; } \\
\text { complements; omitted }\end{array}$} & \multicolumn{2}{|c|}{$\begin{array}{l}\text { temporal adverbs; locational } \\
\text { adverbs; complements; } \\
\text { omitted }\end{array}$} \\
\hline & $\begin{array}{l}\text { Token } \\
\text { Distribution }\end{array}$ & $83 \%$ & $12.2 \%$ & $4.6 \%$ & $0.2 \%$ \\
\hline \multirow[t]{2}{*}{$\begin{array}{l}\text { Semantic } \\
\text { features }\end{array}$} & $\begin{array}{l}\text { Information } \\
\text { structure }\end{array}$ & \multicolumn{2}{|c|}{$\begin{array}{l}\text { NP(new information; focus) } \\
\text { There(location)(old } \\
\text { information) }\end{array}$} & \multicolumn{2}{|c|}{$\begin{array}{l}\text { There(location) (new } \\
\text { information;focus) } \\
\mathrm{NP} \text { (old information) }\end{array}$} \\
\hline & $\begin{array}{l}\text { Constructional } \\
\text { meaning }\end{array}$ & $\begin{array}{l}\text { existence } \\
\text { of sth. }\end{array}$ & $\begin{array}{l}\text { occurrence of } \\
\text { sth. }\end{array}$ & $\begin{array}{l}\text { picking out } \\
\text { the position } \\
\text { of sth. static }\end{array}$ & $\begin{array}{l}\text { picking out the } \\
\text { position of sth. } \\
\text { in motion }\end{array}$ \\
\hline
\end{tabular}

\section{CONCLUSION}

In this paper, we elaborate the constructional hierarchy and constructional features of the There Construction including the existential There Construction and the deictic There Construction. The classification of the There Construction supplements Lakoff' s assumption and outlines his schematic framework. According to data searched out from COCA, the most distinctive syntactic distinction between these two constructions resides whether NPs are definite. If they are definite, they belong to the deictic There Construction, otherwise, the existential one.

Syntactic relations and differences between the existential There Construction and the deictic There Construction are evacuated deeply. Both VP in these two constructions may be accompanied by different tense including simple present tense, simple past tense, and abbreviation form of Is and Are. Besides, $\mathrm{V}$ in the existential There Construction could be used in more semantic types than those in the deictic There Construction.

Third, besides overt syntactic distinctions, semantic meaning from static existentials to dynamic existentials in the existential There Construction and from the static deictics to the dynamic dectics in the deictic There Construction have been fully noticed. Constructions with BE denotes static meaning of existence or picking out something static, while constructions with $\mathrm{V}$ denote dynamic meaning of occurrence or picking out something in motion.

\section{ACKNOWLEDGMENT}

I am immensely grateful to my family members for always being there with their consistent loving support. Without their understanding and encouragement, I cannot overcome all the difficulties during the process of the paper writing. This paper is also dedicated to them.

\section{REFERENCES}

[1] Biber, D., et al., Longman grammar of spoken and written English (vol 2), Cambridge, MA: MIT Press, 1989.

[2] Bolinger, D., Meaning and form, London \& New York: Longman, 1977.

[3] Bull, W., "Related Functions of Haber and Estar", Modern Language Journal, pp. 119-123, 1943.

[4] Close, R. A., A reference grammar for students of English, London: Longman, 1977.

[5] Dixon, R. M., A semantic approach to English grammar, Oxford: Oxford University Press, 2005.

[6] Hanny, M., English existentials in functional grammar, Dordrecht, Holland: Foris Publications, 1985.

[7] Huddleston, R. D., \& Pullum, G. K., The Cambridge grammar of the English language. Cambridge: Cambridge University Press. 2002.

[8] Hu G., A probe into the there-sentence structure, Changsha: Hunan University Press, 1988.

[9] Lakoff, G., Women, fire, and dangerous things: What categories reveal about the mind, Chicago: University of Chicago Press, 1987.

[10] Leech, G. Meaning and the English verb, London: Longman, 1971.

[11] Leech, G. English grammar for today, London: MacMillan, 1982.

[12] Lumsden, M., Existential sentences: Their structure and meaning, London, New York \& Sydney: Croom Helm, 1988.

[13] Lyons, J., Semantics (vol. 2), London \& New York: CUP, 1977. 
[14] Klaus V. H., "Specificity and definiteness in sentence and discourse structure". Journal of semantics, vol. 19, pp. 245-274, 2002.

[15] Mcnally, L., "Existential sentences without existential quantification", Linguistics and Philosophy, vol. 21, pp. 353-392, 1998.

[16] Milsark, G. L., Existential sentences in English, New York \& London: Garland Publishing, Inc., 1979. 